\title{
From Group-based Learning to Cooperative Learning: A Metacognitive Approach to Project-based Group Supervision
}

\author{
Christopher Cheong \\ School of Business IT \& Logistics, RMIT University, Melbourne, \\ Victoria, Australia
}

christopher.cheong@rmit.edu.au

\begin{abstract}
Group-based learning creates an environment in which students can practice, gain, and improve soft skills such as leadership, communication, social, and conflict resolution skills. However, simply placing students in groups and creating group-based assessment tasks will not necessarily result in students developing and practicing these skills. Instead, specific approaches, such as cooperative learning in this case, need to be followed to ensure students develop theses skills. Of the six principles of cooperative learning, the first four (positive interdependence, accountability, team formation, and team size) can be addressed in the manner in which the groups are formed, its size, group assessment tasks, and the way in which the tasks are assessed. The remaining two principles, cognitive development and social development, can be addressed through a metacognitive approach to group supervision, which are detailed in this paper.
\end{abstract}

Keywords: group-based learning, cooperative learning, supervision, information systems

\section{Introduction}

Information systems professionals are often involved in handling large and complex tasks, such as requirements gathering, analysis, design, implementation, testing, and deployment of software systems, which cannot be addressed individually. In such circumstances, soft skills related to group work (also referred to as people or generic skills), such as communication, collaboration, organization, decision-making, conflict resolution, leadership, social, and critical thinking skills, are important. These skills are difficult to impart to students through teaching material alone. Students should be provided with the opportunity to practice group work skills in a learning environment that simulates that of their future work places. Furthermore, it is important to assess the students' performance in relation to the group in a manner that encourages desirable skill devel-

Material published as part of this publication, either on-line or in print, is copyrighted by the Informing Science Institute. Permission to make digital or paper copy of part or all of these works for personal or classroom use is granted without fee provided that the copies are not made or distributed for profit or commercial advantage AND that copies 1) bear this notice in full and 2) give the full citation on the first page. It is permissible to abstract these works so long as credit is given. To copy in all other cases or to republish or to post on a server or to redistribute to lists requires specific permission and payment of a fee. Contact Publisher@InformingScience.org to request redistribution permission. opment.

Although there are a number of advantages associated with group work, in particular the development of the aforementioned skills, group work can be difficult to teach and assess. One of the most prominent issues is unequal contribution of group members. Less motivated students have the tendency to let more motivated students drive the group 
and carry out most of the work. This leads to a subset of the group developing and learning substantially more than others.

From a teaching and learning perspective, it is important to firstly structure group tasks and assessment strategies to address such issues. That is, group tasks and assessments strategies should be designed such that industry group work is replicated in a learning environment in which students are able to practice their group work skills and are appropriately and fairly assessed. Secondly, and perhaps more importantly, it is necessary to ensure students are developing desirable group work skills and attitudes.

From an informing perspective, of which education is a subset, there is an obvious flow of information from the educator (i.e., the "informer") to the learner (i.e., the "client"). However, a perhaps less obvious flow is that of student-to-student (or peer-to-peer). Although this type of information flow does exist informally between students, it is particularly emphasized in, and plays and important part of, group-work. Thus, it is important to understand its part in group work and also how to use it to further ensure students are developing desirable group work skills and attitudes.

In this paper, exploratory work in developing an approach to group-based learning (i.e., group work) in an undergraduate final year information systems capstone course is explained and analyzed. The capstone course is so named as it is an integrative course in which students apply the knowledge and skills they have acquired throughout the duration of their studies to an assigned real-world project.

Students undertaking the capstone course are divided into groups of six and each group is assigned a real-world, industry-based, and non-mission critical project to complete. Groups are also assigned an academic supervisor to guide them through the software development life cycle to complete the project. The intent of the course is for students to consolidate their previously acquired experience, skills, and knowledge throughout the program, and to work as a group to complete a real-world project for an industry-based client. In this regard, the course can be seen as a final test of readiness for the students.

The course structure and assessment are suitable for group-based learning, which is favourable as it develops social interactions skills, allows for management of conflict resolution in a supportive environment, and creates strong social support systems (D'Souza \& Wood, 2003). However, simply placing students into groups or creating group-based assessment tasks will not necessarily result in students developing these skills (Hron \& Friedrich, 2003). In order to ensure students develop these skills, it is necessary to follow approaches specifically developed for these purposes (E. G. Cohen, 1994; Slavin, 1996). Cooperative learning is one such approach.

\section{Cooperative Learning}

Cooperative learning covers a range of group-based learning approaches (Damon \& Phelps, 1989). It can be seen as a set of different instructional methods in which student are encouraged by the teacher to cooperate in learning (Slavin, 1987). Its focus is on the interaction between students over the subject matter, which, depending on the quality of the interaction, can result in different modes of learning.

Equality and mutuality are two dimensions that can be used to determine the quality of interactions (Damon \& Phelps, 1989) and consequently identify the modes of learning. Equality relates to the flow of instructions within the interaction. That is, equality is not a unilateral flow of instructions; all individuals involved in the interaction give and take instructions to and from each other (Damon \& Phelps, 1989). Mutuality refers to the interaction's engagement; it should be extensive, intimate, and connected (Damon \& Phelps, 1989). The following explains three different 
modes of learning that occurs between two peers, namely peer tutoring, cooperative learning, and peer collaboration (Damon, 1984; Damon \& Phelps, 1989), based on different degrees of these two dimensions.

In peer tutoring, there is a disparity in competency between the two peers. The more competent individual (i.e., the "expert" peer) takes charge of the interaction and directs the learning for the less competent individual (i.e., the "novice" peer) (Bloom, 1976; E. G. Cohen, 1986; Damon \& Phelps, 1989; Hartup, 1983). As the expert peer has greater control over both the material and the interaction mode, there is low equality and mutuality. This type of interaction is similar to the traditional teacher-student model. However, one difference between peer tutoring and the teacherstudent model is that the expert peer does not have the same degree of expertise over the material as the teacher. That is, the disparity between the peer imparting the knowledge and the peer receiving it is not as great as the disparity between teacher and student. Additionally, there is also a disparity between the expert peer's instructional skills in comparison to the teacher's. This can be an advantage as the novice peer may more likely express opinions and ask questions of his or her peer compared to his or her teacher (Damon \& Phelps, 1989).

Cooperative learning is a group-based activity in which the group (typically containing $5-6$ individuals) is presented with a task to be address or solved. The individuals in the group usually have similar levels of competencies, and the individuals may be assigned roles, which can later be exchanged between individuals (Damon \& Phelps, 1989). Thus, cooperative learning is high on equality. In some versions of cooperative learning, a sub-division of labour approach is used and this results in some individual learning. Thus, mutuality is variable (usually between low and moderate (Damon \& Phelps, 1989)) and dependent on the method of cooperative learning involved. These include individual work, peer tutoring, discussions, feedback, explanations, joint explanations, and evaluation (Peklaj, 2006).

In peer collaboration, two relative novices who cannot solve a task individually collaborate to do so together (Ames \& Murray, 1982; Bearison, Magzamen, \& Filardo, 1986; Damon \& Killen, 1982; Damon \& Phelps, 1989). The individuals have approximately the same competency level and, unlike cooperative learning, they work together at all times on the same problem. This results in more engaging interactions, and, thus, both equality and mutuality are high.

Although cooperative learning covers a range of group-based learning approaches, it can be said to have these principles (taken from Oxford, 1997):

1. Positive interdependence: Gains for one person are associated with gains for others; can be attained through structuring the goals, rewards, roles, materials, or rules

2. Accountability: Every person is accountable through individual grading and testing; the group is accountable through a group grade; improvement scores are possible

3. Team formation: Teams are formed in various ways - randomly; by student interest; by the teacher using specific criteria (heterogeneously, representing different characteristics such as aptitude or gender; or homogeneously)

4. Team size: Groups of smaller than seven members usually work best

5. Cognitive development: This is often viewed as the main goal of cooperative learning

6. Social development: Development of social skills such as turn taking, active listening, and so forth can be as important as cognitive development

Cooperative learning has a number of benefits over individual learning, one of which is that learners tend to use higher order thinking more frequently (Peklaj, 2006). Although there are differing definitions of higher order thinking, it generally refers to the ability of autonomous thinking and making reasoned judgements (Paul \& Binker, 1990). It also refers to having metacogni- 
tive awareness and problem-solving capacities (McLoughlin \& Luca, 2000). These are all qualities that are needed in a well-rounded information systems graduate.

\section{Informing in Group Work}

Another dimension that can be used to determine the quality of interactions is that of the underlying theme of information flow in group work. This can be explored through the transdiscipline of informing science (E. B. Cohen, 2009), which can be viewed as a superset of education.

During its inception, this transdiscipline was particularly focused on the direct information flow from an informer to a client. However, as the transdiscipline matured, its focus extended to include more complex informing situations, such as peer-to-peer informing.

In the case of education, the initial focus of informing obviously relates to information flows between an instructor or supervisor (i.e., the informer) and a learner (i.e., the client). With respect to cooperative learning (refer to the Cooperative Learning section), this can be used to explain peer tutoring, which is similar to the traditional teacher-student model. However, the later and broader definition is needed to adequately view cooperative learning and peer collaboration as they involve student-to-student (i.e., peer-to-peer) informing (Gill \& Cohen, 2008).

Project-based group work is a complex informing situation in which student-to-student informing is particularly important as the majority of the work and learning occurs between students when they are away from their project supervisor or instructor. Students can alternately act as "clientsenders" or "client-recipients" (Gill \& Cohen, 2008), depending on their assigned roles (refer to the Cooperative Learning section), in the group. For example, a student in the role of "database administrator" will be a "client-sender", as he or she is strongly motivated to inform other clients (i.e., group members) about information to assist them complete various database-related tasks of which the database administrator has overall responsibility. That same student when assisting the student in the role of "project manager" will be a "client-recipient" as he or she will be enquiring for information from project manager to complete his or her tasks. That is, as a client-recipient he or she will seek information to complete his or her tasks.

\section{Course History and Details}

In the information systems program in which the students undertake the capstone course in their final year, students are taught a mixture of business and IT courses. The IT courses are generally business-oriented. Originally, the students completed a different IT course in the last semester of their final year. The course challenged students to consolidate skills and knowledge acquired thus far and to apply it to creating a web-based enterprise application. The web-based enterprise application was developed using Java 2 Enterprise Edition (J2EE) and students were also taught a number of new concepts and topics (i.e., not learnt in previous courses), such as testing and deployment.

In 2005, it was decided to create a new course with the same philosophy, i.e., a course to consolidate the knowledge and skills of students as a final test of readiness. Thus, the capstone course was created. The focus of the capstone course is to create a learning environment in which students are able to engage in group work and both the product and the process of developing it are assessed. The course is detailed in the following section.

\section{Capstone Course}

As previously mentioned, in the capstone course, students are divided into groups of six. Each group is assigned a real-world, non-mission critical, industry-based project to complete. The project is real-world and industry-based as it is to be developed for a real business and students are to 
interact with a real client. Each group is also assigned a supervisor to guide them during the course of the project.

The projects generally involve the creation of an information system with a graphical user interface and a database back-end. Groups are free to choose appropriate methodologies, platforms, frameworks, and technologies to satisfy user requirements and complete their projects successfully.

Typically, members of each group assign themselves to the following pre-determined roles: (1) project manager, (2) business analyst, (3) developer/programmer, (4) database administrator, (5) usability analyst, and (6) tester. Although members have specific roles, they are not to operate solely in that capacity. That is, they are responsible to lead the group in that particular role and must assist other members with other tasks. For example, it is not expected that the database administrator only will deal with all matters regarding the database back-end; he or she is able to delegate database-related tasks to other members if appropriate. However, the student in the database administrator role accepts overall responsibility for tasks related to the database.

The course is structured such that a group must meet with its supervisor once a week to report work progress, discuss any issues that have arisen, and plan for future work. Groups must also provide their supervisors with weekly summary reports and attend seminars, which are recapitulations of topics that students have studied previously and will require for the project.

The course is divided into four phases based on the Software Development Life Cycle (SDLC). Groups are required to submit appropriate assessable deliverables at the end of each phase. The phases are as follows:

- Phase 1: Requirements model and user interface prototype Groups are required to liaise with their supervisor and meet with their assigned clients in order to gather requirements and build a requirements model. The groups are also required to create a working user interface prototype. Major deliverables are the requirements model, working user interface prototype, and a project plan.

- Phase 2: Design model and prototype implementation

The system must be designed and a prototype must be implemented in this phase. Major deliverables include a design model, a test plan, infrastructure model, and a working prototype (including a presentation of it).

- Phase 3: Complete system development

The system must be completed in this phase. Major deliverables are the completed system and a presentation of it.

\section{- Phase 4: System deployment}

The groups must prepare deployment documents and finalize the implementation. Major deliverables are the working system, completed test results and usability analysis, a system implementation plan, and documentation (both user and technical). At the end of this phase, all the groups gather and present their work to each other.

Note that the groups are not instructed on what methodology or technologies to use. They are required, with the guidance of their supervisors, to determine the most appropriate ones for their particular projects. 


\section{Using Metacognition for Supervising Group Work}

In 2007, the author was appointed as a supervisor for a group of students undertaking the course. As a new and junior academic, he had experience in software engineering, managing and leading software teams, and teaching software development, but had no experience in supervising a group of students to analyze, design, develop, and test an information system. With advice from more experienced colleagues, and drawing on personal experience of being supervised as a $\mathrm{PhD}$ candidate, the author managed to successfully guide his initial (semester 2 of 2007) and subsequent (semester 1 of 2008) groups of students to succeed in the course. The supervisory approach used (refer to the Supervisory Approach section) is firstly described followed by details of how the two groups were supervised in the chronological order of the phases of the course (refer to the Capstone Course section).

\section{Supervisory Approach}

Although in title the author was the "supervisor" of the group, he did not believe it appropriate to act as such. A supervisor is expected to oversee the project, to instruct subordinates (in this case, the students), and to be responsible for the project. While this was one approach that could have been taken, it would rob the students of some of the experiences of group work and simulation of real-world work groups. Instead, the philosophy to the approach taken was to act as a facilitator or advisor rather than a supervisor.

As a facilitator, the author would allow the group to manage the project itself and provide suggestions rather than instruct the students. More importantly, the author would guide the group through decisions it would make. This is important as it empowers the group and gives it both ownership of and responsibility for the project. It also led to better internal motivation for the group members.

Acting as a facilitator was deemed to be more appropriate because the students have learnt and practiced how to carry out each of the phases of the SDLC in previous courses. Although they may have carried out the phases separately in different courses, they should be able to consolidate their skills and knowledge to complete the capstone project. Furthermore, at this level, if the students are not familiar with particular aspects of the SDLC, they should be able to research and learn by themselves with minimal guidance.

The students expected the author to act as a supervisor, and were initially surprised by the approach taken. After the completion of the course, one student stated, "At the first meeting, I thought, 'Right, he'll [the supervisor] tell me what to do and I'll just do it.'... I was in for a big surprise!"

\section{Group Differences}

A major difference between the two groups of learners that were supervised was the manner in which they were formed. The group of 2007 (Group 1 henceforth) was naturally formed. Five of six members were friends and had worked together prior to starting the capstone course. The sixth member was added to the group by the course coordinator and had not previously worked with the other members. The friends of the group facilitated the initiation of the new member and the group bonded quickly as most of them were familiar with each other's working habits.

The group of 2008 (Group 2 henceforth) was artificially created specifically to undertake the capstone course. Only two members were friends and had previously worked together. This group was slower to bond and there were some initial difficulties between members, which lead to arguments and dissatisfaction (this is elaborated upon in the Phase 1: Requirements Model and User Interface Prototype section). 


\section{Phase 1: Requirements Model and User Interface Prototype}

This phase is typically hectic, as group members are required to get to know each other and their work habits as well as complete the task at hand. The core tasks to be carried out in this phase contribute to the difficulty as the group must meet with the client and gather requirements for the system to be design and developed. Additionally, a number of preparation tasks must be carried out in this phase to reduce possible difficulties in later phases. For example, an appropriate process and system must be selected to manage document and software change control. Group 1, took their supervisor's ("supervisor" will be used interchangeably with "author" henceforth) suggestion and spent more time compared to Group 2 investigating this and had fewer difficulties with version control in later phases. Group 2's approach to version control was less systematic; this led to difficulties, such as bringing outdated versions of documents to meetings.

Although students had learnt in previous courses how to gather requirements, they had only done so through case studies and had never interviewed a real-life client. Both Group 1 and Group 2 had initial difficulties with this phase, and both groups had to meet the client more than once to adequately gather requirements. The supervisor purposely did not attend the meeting with the client as he wanted the groups to carry out this task by themselves and learn from their mistakes.

In preparation for the initial client meeting, the supervisor suggested for the groups to prepare an interview script, including appropriate questions to ask the client. When the groups presented the interview script and questions to the supervisor, he asked them to carry out a self-review rather than for him to assess them. Although the groups believed the questions to be appropriate, in the supervisor-and-students meeting following the students' initial client interview, it became apparent to them that they would need to meet the client more than once in order to gather requirements properly.

In this phase, Group 1 was more efficient as they were a naturally formed group and most members were friends and had previously worked together. Group 2, the artificially formed group, had difficulties with this task. There was a big conflict between the project manager and the usability analyst related to personality differences and work methods. The conflict was significant enough for the project manager wanting the usability analyst to leave the group. Rather than resolve the conflict for the group, as is expected from a supervisor, the author adhered to his role as facilitator and provided the group with conflict resolution documents and asked them to resolve their own group issues.

The group members managed to resolve the issue themselves without further intervention from their supervisor. Oddly, the act of resolving the conflict themselves actually allowed members to bond and become closer. It gave the members an opportunity to get to know one another. After the resolution, the group was able to work cohesively together without any further inter-personal issues.

\section{Phase 2: Design Model and Prototype Implementation}

By the start of phase 2, group members have typically bonded and adjusted to each other's work habits and this allows the groups to focus on the tasks to be carried out. An important group decision in this phase is what design methodology to choose. With both groups, the supervisor asked them to investigate the differences between the methodologies they had studied and to determine which would be more appropriate. The choice was entirely left to the groups and they made the appropriate selection. In both cases, the groups choose an object-oriented methodology.

Next the supervisor suggested that the groups review their knowledge of object-oriented design and to explain what they intended to do, i.e., the process they intended to follow and the diagrams 
they intended to use. Throughout this phase, the groups presented the designs in the supervisorand-students meetings as they progressed each week.

More guidance was required from the supervisor in this phase, especially in checking the validity of the designs the groups created. It was tempting to simply explain correct approaches to the students or instruct them in what had to be carried out, especially after they had attempted and been unsuccessful a number of times. However, staying in the role of facilitator, the supervisor questioning the students about various parts of their design and led them to understand the errors or issues present.

An interesting occurrence worth mentioning is that Group 2 asked their supervisor for his opinion of their deliverable for this phase and asked him what mark he thought they would receive. Instead of providing his opinion, the supervisor asked them to assess it themselves and to tell him what mark they thought they would receive. The supervisor believed it would be important for them to be able to self-assess their own work. When the students received their result for their assessment, they received a mark significantly higher than what they estimated and were extremely happy with their marks. They also understood the value of self-assessment and were more confident to carry on with the following phases.

As the groups are required to present the prototype system to their supervisors and preferably to their clients as part of the assessment in this phase, their supervisor suggested for the groups to take the opportunity to gather more feedback from their clients. Group 1 delivered a mock presentation to their supervisor to review before actually delivering the real presentation to the client. In the initial version of their presentation, they presented the features of the system and some design documents. Their supervisor's feedback was that the presentation was not engaging and that they should think of if from the perspective of their audience, who had limited computer literacy.

Group 1 then revised their presentation and "thought out of the box" to make it more engaging. Instead of simply presenting the features of the system, they devised a real-life scenario in which they allowed their client to operate the prototype system and instruct her on what to do. From this hands-on experience, the client was able to give them valuable feedback about the system, its suitability, and its usability from her perspective. Unfortunately, Group 2 was in limited contact with their client (not of their own choosing) and was unable to carry out a similar activity.

\section{Phase 3: Complete System Development}

This phase is perhaps the most arduous one for the groups as they must complete the working system, in addition to meeting deadlines for assignments in other courses that they undertake simultaneously. Compared to the first two phases, the groups required less supervisor guidance in the third phase as it mainly involves implementing the bulk of the system and, typically, the students are able to implement most of the system and only raise difficult issues that they cannot resolve for guidance.

Although the groups are supposed to have completed the entire system at the end of this phase, there is still some scope for further (minor) modifications in the following phase, which involve installing and deploying the system (refer to the Phase 4: System Deployment section). Additionally, as the groups were required to deliver another presentation of the working system to their supervisors and preferably their clients, Group 1, once again decided to use the same presentation approach to gather more feedback from their client given their prior positive experience. Although having tried, Group 2 was once again unable to contact their client. (It is sometimes the case that clients do not follow through with a project. In such a situation, the group of students continue to complete the project regardless as it is a piece of academic assessment for them). 


\section{Phase 4: System Deployment}

As this phase is about system deployment, the groups are required to deliver the completed system and various related documents such as test plans with test results, usability analysis report, system implementation plan, and both technical and user documentation. Generally, this is a difficult time period for the students as they must complete the project and sit examinations for other courses in the same time period. Thus, the students in the role of project manager were advised to ensure they factor in each group members' availability and exam preparation into their planning.

Students are familiar with most of the deliverables in this phase as they have created and used them in their previous studies. However, the most challenging part of this phase is the usability analysis. In the program, there is an elective course on usability analysis and none of the students in both groups had studied it. Most of the students have no idea how to even start on this part and, as their supervisor is not an expert in usability analysis, he suggested they make an appointment to see the lecturer of the usability analysis course. The students in the role of the usability analyst of both groups contacted the lecturer of the course and even carried out a small real-life evaluation of their system.

Apart from the advice on usability analysis, this phase was much like Phase 3 in that the groups required less supervisor guidance, as they were quite knowledgeable in the tasks to be performed. Although, their supervisor gave them more motivation and encouragement as it was a stressful time period for the students.

\section{Discussion}

The structure of the capstone course is conducive to cooperative learning as it abides by two of its principles, namely principles 3 and 4 (refer to the Cooperative Learning section).

Principles 3 and 4 are related to team formation and size respectively. In accordance to those principles, the groups in the course are formed in various ways (e.g., Group 1 was formed naturally whilst Group 2 was created by the course coordinator) and the groups contain less than 7 individuals (both groups had 6 members).

The allocation of group members to specific roles also contributes to cooperative learning. On a psychological level, it gives the students a sense of responsibility, expertise, and leadership in their groups as each student is allocated to a specific role with associated responsibilities of rolerelated tasks. Furthermore, as the other group members are to assist in all tasks (and not only their assigned roles), each student is able to act as a leader in his or her role and able to delegate tasks. This group structure provides all students in the group (i.e., not just the student assigned as the project manager) the opportunity to practice leadership skills and to alternate between "clientsenders" and "client-recipients" (refer to the Informing in Group Work section). Thus, equality is high as there is no superiority associated to any single role. Mutuality varies between moderate (a sub-division approach is used within the groups and some individual work is required) and high (groups members are to assist each other in all tasks). The appointment of students to roles and the expected responsibility and leadership associated with the appointment also imbues the students with a sense of empowerment and ownership, which leads to greater internal motivation.

The assessment tasks, especially the manner in which they are assessed, are also conducive to cooperative learning. The deliverables from all four phases (refer to the Capstone Course section) are assessed as group assessments, that is, all members receive the same group mark. This establishes positive interdependence (principle 1), as a group member's gain is associated with the gains for the group. Furthermore, two individual interviews establish accountability (principle 2) as these assessment lead to individual grading and testing of the different contributions of each group member. 
Thus, the first 4 principles of cooperative learning are relatively easy to establish through course structure and assessment tasks. The last two principles, cognitive development and social development, are more challenging.

In the course, there are two facets to social development: (1) social development between student and supervisor and (2) social development between group members. The first facet, "informer to client" informing (refer to the Informing in Group Work section), can be directly controlled by the supervisor through weekly meetings and other communications (e.g., emails, phone calls, etc). Weekly meetings between groups and supervisors are useful for both the group members and the supervisor. The group obviously benefits from meeting with its supervisor to seek advice, and address issues and difficulties. The supervisor also benefits as he or she is constantly monitoring the groups. This allows the supervisor to see the group dynamics and identify issues that may arise between group members. The supervisor also witnesses each student's social ability, which is an important soft skill in group work, and this allows the supervisor to make better assessments of the students' capabilities when marking them on such soft skills and group contribution.

The most important part of the weekly supervisor-group meeting is forming a good relationship between the two. This is extremely important, as the group must, to some degree, trust their supervisor and these social interactions allow for this trust to be built and maintained.

It is also important for the supervisor to facilitate group discussions during the meetings. For example, if some group members are particularly passive, the supervisor should engage them in discussions by asking their opinions on particular issues. In contrast, the supervisor must also control group members who are overly active in discussions and encourage an environment in which equality is high.

The supervisor is able to gauge the mutuality of the group (i.e., individual contribution and engagement) through the weekly interviews. As a rough measure, students are asked to keep track of the number of weekly hours they spend on their allocated tasks.

The majority of social development between group members, i.e., "client to client" informing (refer to the Informing in Group Work section), occurs away from the supervisor as group members will meet frequently to work together on the project. These meetings allow group members to interact and this social element is important for them to learn soft skills required in group work. Thus, the supervisor does not have direct control over the social development between group members; however, he or she may be able to gauge and influence this through the individual interviews and ad hoc individual conversions. It is particularly important to monitor the social development between group members as conflict may arise, as was the case with Group 2.

Cognitive development (principle 5) is dependent on how the interaction within groups is structured. The approach used in the course, i.e., group investigation of different projects, is conducive to cooperative learning and develops problem solving, research, and argumentation skills (Peklaj, 2006).

Cognitive development also depends on how the supervisor interacts with the group and the approach he or she takes. In the approach to group supervision described in this work (refer to the Supervisory Approach section), the supervisor acted more as a facilitator rather than a "typical" supervisor. That is, the students are not instructed on what has to be carried out, instead the students are allowed to manage both their group and their project themselves. They are guided through decisions that have to be made and are assisted in determining and weighing their options. However, unless completely wrong, the supervisor allows groups to make decisions themselves.

As previously mentioned (refer to the Supervisory Approach section), by not instructing the groups and allowing them to decide for themselves, they are not only empowered, but also re- 
sponsible for the development of their group and the completion of their project. This places a sense of ownership on the students and leads to greater internal motivation.

The communication and social interaction between a supervisor and his or her group is also very important. It is essential to establish a good working relationship with the groups as it (1) simulates real-life working environments, processes, and responsibility structures, and (2) building trust from supervisor to group is as important as building trust between group members. The approach used is to keep the meetings casual, but yet purposeful. The student chairing the meeting is allowed to prepare the agenda and run the meeting, and the supervisor only interrupts if the meeting is not efficient. Ultimately building a good relationship between a supervisor and a group will not solely depend on the supervisor, but also the group members.

Although this approach places more stress and pressure on the students, they also gain a lot more. The students are faced with problems and, with some supervisory guidance, they are able to resolve the problems themselves. For example, Group 1 managed to deliver a very interesting presentation and gathered valuable feedback from their client after their supervisor told them that their initial presentation was not engaging enough (refer to the Phase 2: Design Model and Prototype Implementation section).

Although there was initial surprise to this supervisory approach (refer to the Supervisory Approach section), once students understand the reasons for selecting such an approach, they learn to benefit from it: "use your supervisor as your guide and source of advice rather than your instructor as it's you who is undertaking the capstone project."

Through this approach, students are able to experience a realistic simulation of a real-life work place and they are also given opportunities to practice soft skills (e.g., self-assessment, communication skills, teamwork, etc.). One student acknowledged that he had learnt a lot about soft skills, such as "providing client services and working as a team." Additionally, it provides the students with a better learning experience, as one student mentioned, "It was also a great opportunity for us [the group] to put some of our skills to use, break out of our comfort zone, and learn some new skills." Students are also better internally motivated and are more likely to develop life-long learning skills and deeper learning.

The students themselves, through numerous comments, were quite content with this approach to supervision. They enjoyed being given responsibility for their own actions and worked at their best. The project manager of Group 1 stated, "The staff involved provided a strong support structure, maximising the benefit we received from the project."

The success of their project has pushed members of Group 1 to continue with their project after they graduated. They persisted in updating the system and have deployed the system that is currently in use by their client. Although this is the ultimate goal of the course, deploying an actual system does not always occur as no support is provided to the client since the students will complete the project and graduate. This achievement was extremely rewarding for the group and their supervisor.

The supervisor has also formed a strong bond with both groups. Members of Group 1 and their supervisor meet on a semi-regular basis and members of Group 2 have expressed interest in meeting but have not yet had the opportunity. Members of Group 1 have also expressed interest in forming a small business to support its product. This is an example of how good group work and working on a real-life business problem can provide opportunities for graduating students to form life-long networks and learning, as one student remarked, "It [the course] gives us the opportunity to start networking and forming groups for future business establishment." 


\section{Conclusion}

Group-based learning provides a good situation in which students can practice, gain, and improve soft skills such as leadership, communication, social, and conflict resolution skills. However, more needs to be done than to simply create group-based assessment tasks and place students into groups; measures specifically designed for cooperative learning must be followed to ensure the development of these skills is encouraged.

Two principles of cooperative learning, team formation and team size, can be attained by using a course structure in which teams can be formed in various ways and the size is limited to be less than 7 members. Two additional principles of cooperative learning, positive interdependence and accountability, can also be attained by assessing the group tasks as a whole and individual member contributions.

The two remaining principles of cooperative learning, social development and cognitive development, are more challenging to attain. Social development will largely occur away from the supervisor; however, the supervisor does have some control by the way he or she communicates with the group and the relationship that he or she forms with them.

Cognitive development will depend on the supervisor's approach to supervision. Using a metacognitive approach in which the supervisor acts as a facilitator or advisor has been positive. The group should be allowed to manage the project and itself entirely. The supervisor is to suggest rather than instruct. This gives the groups a strong sense of ownership.

The approach outlined in this paper has resulted in a positive experience for the supervisor and groups involved. As the work reported is exploratory, future work is necessary to further investigate this approach.

At the informing level, a way to assess the interaction between students would be necessary. In particular, information about who gave instructions, who received instructions, and how many times, should be recorded and analyzed. This would provide more rigor to the research by allowing for an empirical facet to be added to support how the students' interactions influence cooperative learning.

At a higher overall level, future work should include an evaluation of the approach. The evaluation can be carried out by the use of learning blogs (weblogs) and focus group interviews. Students should keep an individual and reflective blog of their experience in the group and on the project that can later be analyzed. Blogs are effective tools to record student reflections on particular topics (Cobanoglu, 2006). Focus group interviews can then be held with selected students to gain a deeper understanding how effective the metacognitive approach described in this paper is.

\section{Acknowledgements}

I would like to thank the students in the two groups that I have supervised. Through supervising them, I have had the opportunity to develop a supervision style that they have benefited from and that other groups will also benefit from. Furthermore, I would also like to thank my colleagues, Vince Bruno and Maurice Abi-Raad, for their invaluable advice and another colleague, Audra Lukaitis, for providing useful comments on a draft version of the paper. I must also thank Editorin-Chief Grandon Gill and the anonymous reviewers who provided suggestions that have improved the paper. 


\section{References}

Ames, G., \& Murray, F. (1982). When two wrongs make a right: Promoting cognitive change by social conflict. Developmental Psychology, 18(6), 894-897.

Bearison, D., Magzamen, S., \& Filardo, E. (1986). Socio-cognitive conflict and cognitive growth in young children. Merrill-Palmer Quarterly, 32(1), 51-72.

Bloom, S. (1976). Peer and cross-age tutoring in the schools. National Institute of Education monograph, U.S. Department of Health, Education, and Welfare, Washington, DC.

Cobanoglu, C. (2006). An analysis of blogs as a teaching tool as perceived by hospitality management students. Journal of Hospitality, Leisure, Sport and Tourism Education, 5(2), 83-88.

Cohen, E. B. (2009). A philosophy of informing science. Informing Science: the International Journal of an Emerging Transdiscipline, 12, 1-15. Retrieved from http://www.inform.nu/Articles/Vol12/ISJv12p001-015Cohen399.pdf

Cohen, E. G. (1986). Designing groupwork: Strategies for the heterogeneous classroom: Teachers College Press New York.

Cohen, E. G. (1994). Restructuring the classroom: Conditions for productive small groups. Review of Educational Research, 64(1), 1.

D'Souza, S., \& Wood, L. (2003). Tertiary students' views about group work in mathematics. Paper presented at the Educational Research, Risks and Dilemmas - New Zealand Association for Research in Education (NZARE) and Australian Association for Research in Education (AARE) Joint Conference, The University of Auckland, Auckland, New Zealand.

Damon, W. (1984). Peer education: The untapped potential. Journal of Applied Developmental Psychology, 5(4), 331-343.

Damon, W., \& Killen, M. (1982). Peer interaction and the process of change in children's moral reasoning. Merrill-Palmer Quarterly, 28(3), 347-367.

Damon, W., \& Phelps, E. (1989). Strategic uses of peer learning in children's education. In T. Berndt. \& G. Ladd (Eds.), Peer relationships in child development (pp. 135-157). New York: Wiley.

Gill, T., \& Cohen, E. (2008). Research themes in complex informing. Informing Science: the International Journal of an Emerging Transdiscipline, 11, 147-164. Retrieved from http://www.inform.nu/Articles/Vol11/ISJv11p147-164GillIntro.pdf

Hartup, W. (1983). Peer relations. Socialization, Personality, and Social Development, 4, 116-173.

Hron, A., \& Friedrich, H. (2003). A review of web-based collaborative learning: Factors beyond technology. Journal of Computer Assisted Learning, 19(1), 70-79.

McLoughlin, C., \& Luca, J. (2000). Cognitive engagement and higher order thinking through computer conferencing: We know why but do we know how. Paper presented at the Teaching and Learning Forum.

Oxford, R. (1997). Cooperative learning, collaborative learning, and interaction: Three communicative strands in the language classroom. The Modern Language Journal, 81(4), 443-456.

Paul, R., \& Binker, A. (1990). Critical thinking: What every person needs to survive in a rapidly changing world: Center for Critical Thinking and Moral Critique.

Peklaj, C. (2006). Cooperative activity and its potential for learning in tertiary education. Horizons of Psychology, 15(3), 37-50.

Slavin, R. (1987). Developmental and motivational perspectives on cooperative learning: A reconciliation. Child Development, 58(5), 1161-1167.

Slavin, R. (1996). Research on cooperative learning and achievement: What we know, what we need to know. Contemporary Educational Psychology, 21(1), 43-69. 


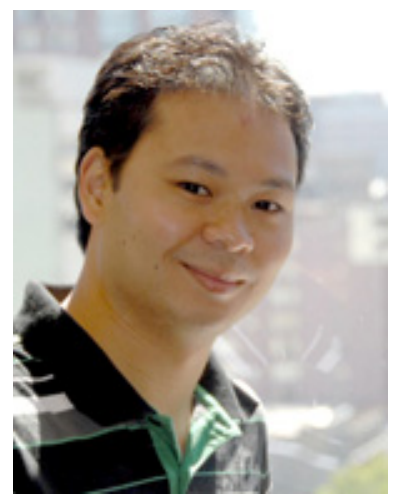

\section{Biography}

Christopher Cheong is a lecturer in the School of Business IT \& Logistics, RMIT University. He holds a Bachelor of Applied Science (Computer Science) (Honors), a Graduate Certificate in Tertiary Teaching and Learning, and a Ph.D. (Computer Science). His research interests involve artificial intelligence, intelligent agents, evolutionary computing, software engineering, and modeling and simulation. 